\title{
The effect of a new in situ precipitation inhibitor on chemical EOR
}

\author{
Khaled Abdalla EIraies
}

Received: 28 September 2012 / Accepted: 16 December 2012/Published online: 9 January 2013

(C) The Author(s) 2013. This article is published with open access at Springerlink.com

\begin{abstract}
Divalent metals cations present in injection water can significantly influence the performance of alkalisurfactant-polymer (ASP) flooding. These cations such as calcium and magnesium react with the added chemicals to form their insoluble salts as precipitations. In this paper, an in situ precipitation inhibitor known as sodium acrylate is used to overcome the precipitation problems prevalent with ASP flooding. Fluid-fluid compatibility tests were performed to examine the performance of the in situ precipitation inhibitor using hard brine having large quantity of divalent metal cations. The effect of the precipitation inhibitor on interfacial tension was also investigated using various inhibitor concentrations. The in situ precipitation inhibitor showed an excellent performance in preventing calcium and magnesium precipitations and the solutions remained clear for 45 days at $80{ }^{\circ} \mathrm{C}$. Further, as the inhibitor concentration increased to an optimal value, an ultra-low interfacial tension of $0.04 \mathrm{mN} / \mathrm{m}$ could be achieved. The advantage of the in situ inhibitor is the use of hard brines without the need for softening the injection water.
\end{abstract}

Keywords Chemically enhanced oil recovery . Interfacial tension - Compatibility test . Calcium and magnesium precipitation

\footnotetext{
K. A. Elraies ( $\square)$

Petroleum Engineering Department, Faculty of Geoscience and Petroleum Engineering, Universiti Teknologi Petronas, Tronoh, Malaysia

e-mail: khaled.elraies@petronas.com.my;

alrayes2006@yahoo.co.uk
}

\section{Introduction}

The combination involving alkali-surfactant-polymer (ASP) has been recognized as a cost-effective chemical flooding process for light and medium oils. The success of this process does not depend only on the identification of a proper alkali, surfactant, and polymer, but also on the way they are combined to produce compatible and effective formulation. In the ASP process, alkali is added to react with the acidic components in crude oil to form an internal surfactant and also to increases the $\mathrm{pH}$ to lower surfactant adsorption (Elraies and Tan 2010). Surfactants are used to decrease the IFT between oil and water while polymer is used to improve the sweep efficiency by providing mobility control (Mohan 2009). Using a combination of these chemicals, the oil recovery is greatly enhanced by decreasing interfacial tension (IFT), increasing the capillary number, and improving the mobility ratio (Pingping et al. 2009).

Recently, there have been many field pilot tests using ASP in USA (Pitts et al. 2006), India (Pratap and Gauma 2004), Venezuela (Clara et al. 2001) and China (Wang et al. 1997; Chang et al. 2006). Daqing oil field in China is one of the earliest and successful fields to apply ASP on a field scale. The pilot tests showed that the oil recoveries were increased by 21.4-23.24\% OOIP using ASP flooding over water flooding (Wang et al. 1999; Li et al. 2003; Cheng et al. 2008; Wang et al. 2008; Hong-Fu, et al. 2008). However, even with these advantages and the success of many other ASP projects, the process is not without problems. One of the major problems in ASP process is the scale formation caused by the reaction between the alkali and concomitant divalent metals cations. The presence of these cations such as, calcium $\left(\mathrm{Ca}^{2+}\right)$ and magnesium $\left(\mathrm{Mg}^{2+}\right)$ ions results in excessive alkali consumption and surfactant precipitation (Mohnot and Chakrabarti 1987). 
Due to the reaction between alkali and $\mathrm{Ca}^{2+}$ and $\mathrm{Mg}^{2+}$ ions, softened water must be used to produce compatible ASP slug. This is due to the fact that hard brine or formation water having high hardness concentration leads to unfavourable solid precipitations and thus reducing the ASP efficiency. Therefore, in situ precipitation inhibitor is proposed in this study to overcome the precipitation problems caused by the divalent metal cations. The work presented in this paper is an extension to our previous effort, but using a commercial surfactant and synthetic brine (Elraies and Tan 2010).

The precipitation inhibitor (sodium acrylate) was generated in situ by introducing acrylic acid and alkali to the injection water. When the acid is added to injection water that contains large quantities of divalent metal cations, the acrylic acid reacts with the sodium ion to form sodium acrylate with an excess amount of acrylic acid. By adding the alkali (sodium carbonate) to the mixture, more sodium acrylate is generated. The sodium acrylate would adsorb at the active growth sites of the metal cations to prevent them from precipitating. The expected reactions that may occur during the preparation are shown below.

$\mathrm{C}_{3} \mathrm{H}_{4} \mathrm{O}_{2}+\mathrm{Na} \rightarrow \mathrm{C}_{3} \mathrm{H}_{3} \mathrm{NaO}_{2}+\mathrm{H}_{2} \mathrm{O}$

$\mathrm{C}_{3} \mathrm{H}_{4} \mathrm{O}_{2}+\mathrm{Na}_{2} \mathrm{CO}_{3} \rightarrow \mathrm{C}_{3} \mathrm{H}_{3} \mathrm{NaO}_{2}+\mathrm{CO}_{2}+\mathrm{H}_{2} \mathrm{O}$

When the calcium and magnesium ions are disabled in the solution, then the surfactant is introduced to the system without any precipitation problems (Elraies and Tan 2010). The influence of the inhibitor on precipitation reaction may be explained in terms of three effects: (a) direct complexation of sodium acrylate with crystal lattice ions in solution; (b) adsorption of sodium acrylate on the crystal surface or at the active growth sites; (c) sodium acrylate may change the ionic strength of the solution and hence increasing the effective solubilities of the calcium and magnesium ions in brine solution (Amjad 1989). The advantage of the in situ inhibitor is the use of hard brines without the need for softening the injection water. This could reduce the cost of chemical EOR process and make it more suitable for environmentally sensitive applications, particularly offshore application.

\section{Experimental methodology}

Material description

Crude oil collected from Angsi I-68 reservoir, offshore Trengganu, Malaysia, was used in this study. The total acid number was $0.478 \mathrm{mg} \mathrm{KOH} / \mathrm{g}$ and the oil density was $0.827 \mathrm{~g} / \mathrm{cc}\left(25^{\circ} \mathrm{C}\right)$. The API gravity was $40.1^{\circ}$ and the live oil had a viscosity of $0.3 \mathrm{cP}$.
Two types of alkalis, namely, sodium hydroxide and sodium carbonate were screened to define the suitable candidate. Both were analytical grade. The acid used in the system was acrylic acid. It is a weak polymer acid and used widely as a precipitation inhibitor. Alpha olefin sulfonate (AOS) was used as a surfactant for interfacial tension (IFT) reduction. Synthetic brine with a total salinity of $35,000 \mathrm{ppm}$ was blended using distillated water. The sodium, calcium and magnesium concentrations were 34,100, 400 and 500 ppm, respectively. All were added as sodium chloride, calcium chloride and magnesium chloride.

Apparatus and methods

The first stage of this study concerns the fluid-fluid compatibility test using the synthetic brine. The fluid-fluid interactions involved were acid-alkali, acid-surfactant, and acid-alkali-surfactant. Different acid-alkali weight ratios were used to investigate the performance of the generated in situ inhibitor in preventing $\mathrm{Ca}^{2+}$ and $\mathrm{Mg}^{2+}$ precipitations. The compatibility tests were conducted at $80{ }^{\circ} \mathrm{C}$ for a period of time, and observations were made by visual evaluation with the formation of solids being indicative of incompatible fluids.

Interfacial tensions (IFT) between different chemical solutions and Angsi crude oil were measured with spinning drop method. Model SVT 20 spinning drop tensiometer equipped with video camera was used to determine the IFT at ambient temperature.

\section{Results and discussions}

Fluid-fluid compatibility tests

\section{Alkali-brine and surfactant-brine interactions}

All alkalis employed in this study were incompatible with the synthetic brine. Sodium carbonate and sodium hydroxide were immediately consumed by $\mathrm{Ca}^{2+}$ and $\mathrm{Mg}^{2+}$ ions to form their insoluble salts as precipitations. Although the AOS has excellent resistance against water hardness, precipitations were formed after 6 days at $80{ }^{\circ} \mathrm{C}$. This is attributed to the interaction between the $\mathrm{Ca}^{2+}$ and $\mathrm{Mg}^{2+}$ and the sulfonate groups of the surfactant. Therefore, in order to use alkali or surfactant with the synthesized brine, the sodium acrylate must be used to keep solutions without precipitations.

\section{Acid-surfactant interaction test}

The compatibility of the surfactant with the synthesized brine was investigated using different acid to surfactant ratios (Table 1). As a mentioned above, the surfactant was 
Table 1 Acid-surfactant interaction test

\begin{tabular}{llllll}
\hline Days & \multicolumn{5}{l}{ Acrylic acid to surfactant weight ratios } \\
\cline { 2 - 6 } & \multicolumn{4}{l}{ Surfactant: } & AOS $=0.6 \%$ \\
\cline { 2 - 6 } & $0 \%$ & $(0.66: 1)$ & $(1: 1)$ & $(1.33: 1)$ & $(1.66: 1)$ \\
& pH: 8.43 & pH: 3.01 & pH: 2.72 & pH: 2.59 & pH: 2.55 \\
\hline 0 & - & - & - & - & - \\
6 & ppt & - & - & - & - \\
9 & ppt & ppt & ppt & - & - \\
15 & ppt & ppt & ppt & ppt & - \\
22 & ppt & ppt & ppt & ppt & ppt \\
\hline
\end{tabular}

ppt precipitation, - clear solution

not compatible with the brine in which precipitations were formed after 6 days. In the presence of acrylic acid, the IOS showed some resistance against water hardness but it is only limited for a period of time. Even with a high acid to surfactant weight ratio (1.66:1), precipitations were generated after 22 days of mixing. This is because the generated in situ inhibitor in not enough to prevent the reaction between the surfactant and $\mathrm{Ca}^{2+}$ and $\mathrm{Mg}^{2+}$. Therefore, alkali must be introduced to react with acrylic acid and produce more sodium acrylate for yielding a clear solution without any precipitations.

\section{Acid-alkali interaction}

Based on the previous compatibility tests, alkalis and surfactant were not compatible with the synthetic brine. It is essential that $\mathrm{Ca}^{2+}$ and $\mathrm{Mg}^{2+}$ ions must be removed from the brine. In this test, alkali and acrylic acid were used together with the brine to form in situ inhibitor. However, the generated in situ inhibitor greatly depends on the acrylic acid to alkali weight ratio and the $\mathrm{Ca}^{2+}$ and $\mathrm{Mg}^{2+}$ concentration in the brine. Hence, it is imperative to evaluate the performance of the in situ precipitation inhibitor using different acrylic acid to alkali weight ratios. The two common alkalis, i.e. sodium hydroxide and sodium carbonate were screened to define the suitable candidate. Table 2 summarizes the results for each acid to alkali weight ratio over 45 days at $80^{\circ} \mathrm{C}$.

As presented in Table 2, the in situ inhibitor was very effective in preventing $\mathrm{Ca}^{2+}$ and $\mathrm{Mg}^{2+}$ precipitations over 45 days at $80{ }^{\circ} \mathrm{C}$. It was also observed that the efficiency of the inhibitor increased as the acid to alkali weight ratio was increased in the case of sodium carbonate. For instance, with a small acid to alkali weight ratio, the produced inhibitor (sodium acrylate) was insufficient to prevent the precipitations. All the acid was neutralized by the added alkali and sodium ions present in the brine. However, when a high acid to alkali weight ratio was used, only the required amount of acid was neutralized by the added
Table 2 Summary of the acid-alkali compatibility test after 45 days at $80{ }^{\circ} \mathrm{C}$

\begin{tabular}{llllll}
\hline Days & \multicolumn{5}{l}{ Acrylic Acid to sodium carbonate weight ratios } \\
\cline { 2 - 6 } & 0 & $(0.66: 1)$ & $(1: 1)$ & $(1.33: 1)$ & $(1.66: 1)$ \\
& $\mathrm{pH}: 10.2$ & $\mathrm{pH}: 7.19$ & $\mathrm{pH}: 6.32$ & $\mathrm{pH}: 5.89$ & $\mathrm{pH}: 5.63$ \\
\hline 0 & $\mathrm{ppt}$ & - & - & - & - \\
3 & $\mathrm{ppt}$ & $\mathrm{ppt}$ & - & - & - \\
17 & $\mathrm{ppt}$ & $\mathrm{ppt}$ & $\mathrm{c}$ & - & - \\
21 & $\mathrm{ppt}$ & $\mathrm{ppt}$ & $\mathrm{ppt}$ & - & - \\
45 & $\mathrm{ppt}$ & $\mathrm{ppt}$ & $\mathrm{ppt}$ & - & - \\
\hline Days & Acrylic acid to sodium & hydroxide & weight ratios & \\
\cline { 2 - 6 } & 0 & $(0.66: 1)$ & $(1: 1)$ & $(1.33: 1)$ & $(1.66: 1)$ \\
& $\mathrm{pH}: 12.4$ & $\mathrm{pH}: 12.0$ & $\mathrm{pH}: 11.6$ & $\mathrm{pH}: 11.2$ & $\mathrm{pH}: 10.5$ \\
\hline 0 & $\mathrm{ppt}$ & $\mathrm{c}$ & $\mathrm{c}$ & - & - \\
1 & $\mathrm{ppt}$ & $\mathrm{ppt}$ & $\mathrm{ppt}$ & $\mathrm{ppt}$ & $\mathrm{ppt}$ \\
29 & $\mathrm{ppt}$ & $\mathrm{ppt}$ & $\mathrm{ppt}$ & $\mathrm{ppt}$ & $\mathrm{ppt}$ \\
\hline
\end{tabular}

ppt precipitation, - clear solution, $c$ cloudy

alkali. The sodium acrylate concentration was increased as a result of the reaction of the alkali and sodium ions with the acrylic acid. The inhibitor adsorbs on the active growth sites of the $\mathrm{Ca}^{2+}$ and $\mathrm{Mg}^{2+}$ surfaces to prevent them from precipitating. As a result, the acid to alkali ratio of 1.33:1 was found to be the optimum ratio in the case of sodium carbonate to prevent any precipitations.

However, in the case of sodium hydroxide, the optimum acid to alkali weight ratio was beyond the highest ratio used in this study. Even with the highest acid to alkali ratio of 1.66:1, precipitations were formed after 1 day of mixing. The acid was fully consumed by the alkali and the generated inhibitor was inadequate to prevent the $\mathrm{Ca}^{2+}$ and $\mathrm{Mg}^{2+}$ precipitations. Therefore, strong alkali (sodium hydroxide) was not considered for selection due its detrimental reaction with acrylic acid and $\mathrm{Ca}^{2+}$ and $\mathrm{Mg}^{2+}$ ions.

\section{Acid-alkali-surfactant interaction}

The compatibility of the acid-alkali-surfactant with $35,000 \mathrm{ppm}$ brine was investigated using different acid to alkali weight ratios for 45 days at $80{ }^{\circ} \mathrm{C}$. Different sodium carbonate concentrations were used to define the optimum alkali concentration in the presence of surfactant. The surfactant concentration was maintained at $0.6 \mathrm{wt} . \%$ and the acid concentration was set proportional to the alkali concentration using the ratio of 1.33:1.

As shown in Table 3, all solutions remained clear for 45 days when the optimum acid to alkali ratio of 1.33:1 was used. This shows the effectiveness of the in situ inhibitor in preventing the $\mathrm{Ca}^{2+}$ and $\mathrm{Mg}^{2+}$ precipitations. This ratio was sufficient in generating the required amount 
Table 3 Effect of different alkali-acid concentrations in the inhibitor performance

\begin{tabular}{|c|c|c|c|c|c|}
\hline \multirow[t]{5}{*}{ Days } & \multicolumn{5}{|c|}{ Acrylic acid + alkali (sodium carbonate) + surfactant $($ AOS $)$} \\
\hline & \multicolumn{5}{|c|}{ Alkali concentration } \\
\hline & $0.40 \%$ & $0.60 \%$ & $0.80 \%$ & $1 \%$ & $1.20 \%$ \\
\hline & \multicolumn{5}{|c|}{ Acid concentration } \\
\hline & $\begin{array}{l}0.53 \% \\
\text { pH: } 6.71\end{array}$ & $\begin{array}{l}0.80 \% \\
\text { pH: } 6.65\end{array}$ & $\begin{array}{l}1.06 \% \\
\text { pH: } 6.64\end{array}$ & $\begin{array}{l}1.33 \% \\
\text { pH: } 6.61\end{array}$ & $\begin{array}{l}1.59 \% \\
\text { pH: } 6.57\end{array}$ \\
\hline 7 & - & - & - & - & - \\
\hline 45 & - & - & - & - & - \\
\hline
\end{tabular}

- clear solution

of in situ inhibitor in the presence of surfactant. Even with a small alkali concentration, the solution remained clear without any precipitation for 45 days at $80{ }^{\circ} \mathrm{C}$.

\section{IFT behaviour in alkali-surfactant-acid system}

The effect of the in situ inhibitor on the IFT behaviour was investigated using different acrylic acid concentrations and $0.6 \mathrm{wt} \%$ for each, surfactant and alkali. Despite the incompatibility between the surfactant and alkali with the synthesized brine, the IFT could be reduced from 9.29 to 0.731 and $4.15 \mathrm{mN} / \mathrm{m}$, respectively. However, the IFT reduced significantly when the surfactant and alkali were combined in the presence of acrylic acid. As indicated in Fig. 1, the IFT decreased drastically with the addition of acid concentration and reached $0.042 \mathrm{mN} / \mathrm{m}$ when the acid concentration was $0.4 \mathrm{wt} \%$. When the acid concentration exceeded $0.4 \mathrm{wt} \%$, the IFT increased slightly but it is still lower than either the surfactant or the alkali alone. In contrast with the compatibility test described above, the IFT reduced from 9.29 to $0.593 \mathrm{mN} / \mathrm{m}$ when the optimum

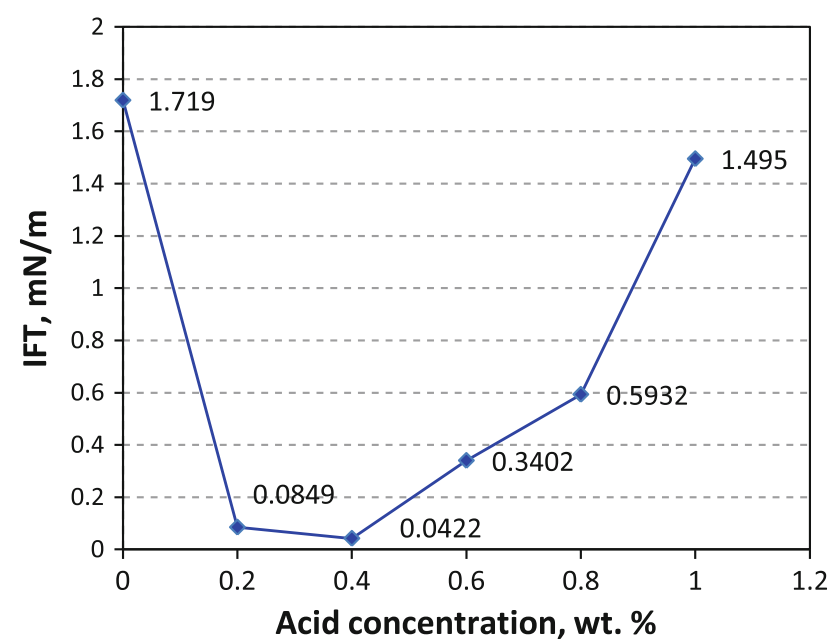

Fig. 1 Effect of different acid concentration on IFT performance (0.6 wt $\%$ alkali and $0.6 \mathrm{wt} \%$ surfactant) acid to alkali weight ratio of $1.33: 1$ was used. This ratio corresponds to alkali and acid concentration of 0.6 and $0.8 \mathrm{wt} \%$, respectively.

\section{Conclusion}

On the basis of the results obtained from this study, the following conclusions are drawn:

1. Alkali-brine and surfactant-brine interactions showed that sodium carbonate and AOS were incompatible with the synthetic brine used in this study. Precipitations were formed from the first day when the solutions were kept at $80{ }^{\circ} \mathrm{C}$.

2. The generated in situ inhibitor (sodium acrylate) was very effective in preventing the calcium and magnesium precipitations over 45 days at $80{ }^{\circ} \mathrm{C}$. The acid to sodium carbonate ratio of $1.33: 1$ was found to be the minimum ratio for generating sufficient precipitation inhibitor in the presence of surfactant.

3. The generated in situ inhibitor might have a negative effect on IFT performance. At low acid concentration (low inhibitor concentration), the IFT reached an ultralow IFT value, whereas, a slight increase in the IFT is observed when the acid concentration increased. This is associated with the change in salinity of the system caused by the generated in situ inhibitor and excess amount of acrylic acid. The generated inhibitor can block the active sits of the $\mathrm{Ca}^{2+}$ and $\mathrm{Mg}^{2+}$ ions resulting in a decrease on the salinity of the system. However, the excess amount of acrylic acid reduces the $\mathrm{pH}$ of the solution, resulting in a surfactant separation from the microemulsion phase.

4. The benefit of the in situ inhibitor is the use of hard water or formation water rather than softened water. This makes the chemical EOR process a cost-effective particularly for offshore field application.

Acknowledgments The author would like to thank the financial support department at Universiti Teknologi PETRONAS (UTP) for sponsoring this project. Also, contributions made by Mr. Shahrul Azwan and Nuzul N. Hashim from Petroleum Engineering Department are also acknowledged.

Open Access This article is distributed under the terms of the Creative Commons Attribution License which permits any use, distribution, and reproduction in any medium, provided the original author(s) and the source are credited.

\section{References}

Amjad Z (1989) Effect of precipitation inhibitors on calcium phosphate scale formation. Can J Chem 67:850-856 
Chang HL, Zhang ZQ, Wang QM, Xu ZS, Guo ZD, Sun HQ, Cao XL, Qiao Q (2006) Advances in polymer flooding and alkaline/ surfactant/polymer processes as developed and applied in the People's Republic of China. JPT 58(2):84-89

Cheng J, Xu D, Bai W (2008) Commercial test of ASP flooding in Daqing Oil Field. SPE 117824, presented at the Abu Dhabi international petroleum exhibition and conference, Abu Dhabi, UAE, 3-6 November

Clara H, Larry JC, Lorenzo A, Abel B, Jie Q, Phillip CD, Malcolm JP (2001) ASP system design for an offshore application in the La Salina field, Lake Maracaibo. SPE 69544, presented at the SPE Latin American and Caribbean petroleum engineering conference, Buenos Aires, Argentina, 25-28 March

Elraies KA, Tan I (2010) Design and application of a new acidalkali-surfactant flooding formulation for Malaysian reservoirs. SPE 133005, presented at the SPE Asia Pacific oil and gas conference and exhibition, October, 18-20, Brisbane, Australia

Hong-Fu L, Dian-Ping X, Jiang J, Xiong-Wen D, Ji-Chun H, Yang J, Yan-Shu X (2008) Performance analysis of ASP commercial flooding in Central Xing2 area of Daqing Oilfield. SPE 114348, presented at the SPE/DOE symposium on improved oil recovery, Tulsa, Oklahoma, 20-23 April

Li H, Liao G, Han P, Yang Z, Wu X, Chen G, Xu D, Jin P (2003) Alkaline/surfactant/polymer (ASP) commercial flooding test in Central Xing2 Area of Daqing oilfield. SPE 84896 presented at the SPE international improved oil recovery conference in Asia Pacific, Kuala Lumpur, Malaysia, 20-21 October

Mohan K (2009). Alkaline surfactant flooding for tight carbonate reservoirs. SPE 129516 presented at the SPE annual technical conference and exhibition, New Orleans, Louisiana, 4-7 October
Mohnot SM, Chakrabarti PM (1987). Alkaline water flooding with a precipitation inhibitor for enhanced oil recovery. United States Patent, 4,714,113

Pingping S, Jialu W, Shiyi Y, Taixian Z, Xu J (2009) Study of enhanced-oil-recovery mechanism of alkali/surfactant/polymer flooding in porous media from experiments. SPEJ 14(2):237-244

Pitts MJ, Dowling P, Wyatt K, Surkalo H, Adams C (2006) Alkalinesurfactant-polymer flood of the tanner field. Paper SPE 100004 presented at the SPE/DOE Symposium on Improved Oil Recovery, Tulsa, Oklahoma, 22-26 April

Pratap M, Gauma MS (2004) Field implementation of alkalinesurfactant-polymer (ASP) flooding: a maiden effort in India. Paper SPE 88455 presented at the Asia Pacific Oil and Gas Conference and Exhibition, Perth, Australia, 18-20 October

Wang D, Zhang Z, Cheng J, Yang J, Gao S, Li L (1997) Pilot test of alkaline/surfactant/polymer flooding in Daqing oil field. Paper SPE 36748 presented at the SPE annual technical conference and exhibition, Denver, October, 6-9

Wang D, Cheng J, Wu J, Yang Z, Yao Y, Li H (1999) Summary of ASP pilots in Daqing Oil Field. Paper SPE 57288 presented at the SPE Asia Pacific improved oil recovery conference, Kuala Lumpur, Malaysia, 25-26 October

Wang F, Yang Z, Wu J, Li Y, Chen G, Peng S, Wang Y (2008) Current status and prospects of ASP flooding in Daqing Oil Fields. Paper SPE 114343 presented at the SPE/DOE symposium on improved oil recovery, Tulsa, Oklahoma, 20-23 April 